\title{
BMJ Open Randomised feasibility study of a novel experience-based internet intervention to support self-management in chronic asthma
}

\author{
Nikki Newhouse, ${ }^{1}$ Angela Martin, ${ }^{1}$ Sena Jawad, ${ }^{2}$ Ly-Mee $\mathrm{Yu},{ }^{2}$ Mina Davoudianfar, ${ }^{2}$ \\ Louise Locock, ${ }^{1}$ Sue Ziebland, ${ }^{1}$ John Powell ${ }^{1}$
}

To cite: Newhouse N, Martin A, Jawad S, et al. Randomised feasibility study of a novel experience-based internet intervention to support self-management in chronic asthma. BMJ Open 2016;6:e013401. doi:10.1136/bmjopen-2016013401

- Prepublication history and additional material is available. To view please visit the journal (http://dx.doi.org/ 10.1136/bmjopen-2016013401).

Received 13 July 2016 Revised 11 October 2016 Accepted 21 October 2016

\section{CrossMark}

${ }^{1}$ Nuffield Department of Primary Care Health Sciences, Health Experiences Research Group, University of Oxford, Oxford, UK

${ }^{2}$ Clinical Trials Unit, Nuffield Department of Primary Care Health Sciences, University of Oxford, Oxford, UK

Correspondence to Nikki Newhouse; nicola. newhouse@phc.ox.ac.uk

\section{ABSTRACT}

Objective: To determine the feasibility of a randomised controlled trial (RCT) assessing the effects of an experience-based website as a resource for the self-management of chronic asthma.

Design and setting: Feasibility, single-blind RCT in 2 regions of England. Randomisation used computergenerated random number sequence in a 1:1 ratio, after baseline data collection, to website access for 2 weeks.

Participants: Adults (age $\geq 18$ years), with clinically diagnosed asthma as coded in their primary care electronic record, prescribed inhaled corticosteroids for at least 3 months in the previous year, were recruited from 9 general practices.

Intervention: The EXPERT asthma intervention is an interactive PC/laptop/tablet/smartphone compatible website designed with extensive input from adults with asthma. It provides experience-based information and aims to support subjective perception of self-efficacy, self-management and improve health status.

Outcome measures: Primary outcomes were consent/recruitment, website usage and completion of outcome measures. Secondary outcomes included Partners in Health (PIH) questionnaire, the Chronic Disease Self-Efficacy Scale, the SF36 and the E-Health Impact Questionnaire. Participant blinding postrandomisation was not possible. The analysis was blind to allocation.

Results: Recruitment target exceeded. 148 participants randomised (73 intervention group). Age range 19-84 years; $59 \%$ female. 121 of 148 (84\%; 62 intervention group) followed up. The median number of logins was 2 (IQR 2-3, range 1-48). Minimal differences of change from baseline between groups; both showed improvement in health state or management of their condition with no significant differences between arms. No adverse events.

Conclusions: Recruitment and retention confirmed feasibility. The trends towards improved outcomes suggest that further research on digital interventions based on exposure to others' personal experiences may be of value in the self-management of chronic asthma. Trial registration number: ISRCTN29549695; Results.

\section{Strengths and limitations of this study}

- Self-management and long-term control of mild to moderate asthma is often poor and tailored online information has been shown to be appealing and effective in the self-management of chronic health conditions.

- Patients proactively choose to view online patient experiences that provide immediate and relevant value and this content is a viable alternative or supplement to traditional 'facts and figures' information.

- The EXPERT asthma intervention website was developed with extensive input from adults with asthma, whose synthesised experiences of selfmanagement formed the intervention content.

- In contrast to previous trials of a similar nature, recruitment rates were high; however, future work needs to consider how to deliver such an intervention in a more pragmatic fashion reflecting 'real world' internet use, and assessing the value of such an intervention as an adjunct rather than an alternative to other sources of information.

\section{BACKGROUND}

Asthma is a major public health problem which is frequently underdiagnosed and undertreated. Globally, the prevalence of asthma is rising, as is the corresponding burden on healthcare systems. ${ }^{1}$ With symptom control as the primary goal of treatment, the extent to which asthma patients play an active role in the day-to-day management of their condition is directly associated with improved outcomes. ${ }^{2}$ However, selfmanagement and long-term control of mild to moderate asthma is often poor and this has been linked to several factors, including complexity of the condition, reluctance to accept diagnosis of a chronic condition, overreliance on health professionals and simple forgetfulness. ${ }^{3}$ While effective management 
of symptoms through appropriate use of medication is vital, education and information play a significant role, with tailored information being shown to be highly effective in asthma care. ${ }^{4} 5$ Asthma patients report unmet information needs and are generally keen to participate in the decision-making process. ${ }^{6} \mathrm{~A}$ disconnection has been reported between patients and healthcare providers views about what patients need to know. ${ }^{7} \mathrm{~A}$ tailored, personalised and proactive approach to symptom management has the potential to improve asthma outcomes primarily by encouraging adherence to medication, ${ }^{9}$ but formal adoption of this approach is wanting.

In recent years, there has been continuous growth in the use of the internet for health information across Europe,${ }^{10}{ }^{11}$ and the role and nature of digital health resources has evolved. Websites are no longer static repositories of information and health resource consumers are now likely to be 'prosumers'-simultaneous consumers and creators of online material-with proactive engagement with online resources, particularly those containing patient-focused content, especially high among those with one or more chronic conditions. ${ }^{12}$ While many early asthma web interventions and digital resources failed to meet patients' needs and expectations in terms of usability and content, ${ }^{13}$ an online interdisciplinary approach has been consistently demonstrated as an attractive and effective source of long-term support for asthma management ${ }^{13-16}$ when compared with usual care. Increasingly, people desire more than traditional forms of fact-based health information and actively go online to seek others' accounts of their own experiences of health and illness, ${ }^{17} 18$ with patients proactively choosing to view online patient experiences that provide immediate and relevant value. In particular, patients experiencing a range of conditions report finding personal testimonials useful in helping them to recognise and reflect on decisions that need consideration, identifying and appraising options, and supporting coping strategies. ${ }^{19}$ There is now a limited but emerging literature looking at the value of novel digital tools which attempt to harness this narrative, experiential information from peers to influence health attitudes and behaviour. ${ }^{19-23}$

However, questions remain regarding the composition of online health information and understanding of what works well, how and for whom. Determining a digital intervention's 'active ingredients' is complex but important: this study attempts to harness and isolate the impact of exposure to online experiential information. Self-management is an established approach to controlling asthma, ${ }^{24}$ and the content of asthma selfmanagement education is well described in UK and international clinical guidelines. ${ }^{25}{ }^{26}$ However, despite the reported effectiveness of asthma self-management, promotion and uptake remains low among patients and healthcare professionals. Factors known to impact on effective self-management include suboptimal social support and perceived ease of access to healthcare, together with a lack of knowledge about how to manage the condition, misunderstandings about therapy, concerns about medication and perceived difficulty with 'fitting' self-management into daily life. ${ }^{27} 28$

Although digital tools have been shown to hold promise in supporting self-management, the best way to communicate information and support through such tools is often unclear. ${ }^{1529}$ The theoretical foundation of the EXPERT intervention was underpinned by a conceptual review ${ }^{18}$ which suggested that observing and participating in the online sharing of personal experience of health and illness could be beneficial in selfmanagement. The conceptual review identified seven 'domains' in which online patients' experiences could affect health: finding information, feeling supported, maintaining relationships with others, affecting behaviour, experiencing health services, learning to tell the story and visualising disease. It was hypothesised that the EXPERT asthma intervention could achieve impact across these domains through the provision of experiential, contextualised information. Exposure to such information could help participants feel more informed about their condition, less alone in managing it and more able to manage relationships with significant others through the mechanisms of social support, social comparison and self-efficacy. In addition, the free-form, non-tunnelled approach to navigating the EXPERT website encouraged recursive engagement with information chosen by the participant as being of particular relevance to them and their specific needs.

Evidence demonstrates that sharing practical and experiential information online is an important part of health-related internet use and that accessing such content is particularly valued by certain patient groups. ${ }^{18}$ The potential for personal stories to improve perceived support has been noted across various health conditions, such as HIV/AIDS, ${ }^{30}$ prostate and breast cancers ${ }^{31}$ and fibromyalgia. ${ }^{32}$ However, far less how is known about how people with asthma view online patient experiences and how they make use of the information they find.

The theoretical review by Ziebland and $W_{y k e}{ }^{18}$ formed the foundation for a programme of work undertaken to develop and test online interventions intending to harness the value of other people's experiences as a new mechanism for delivering health benefit. In this paper, we therefore describe the findings from the first randomised controlled trial (RCT) of a novel 'experienced-based' online intervention for the selfmanagement of chronic asthma. The primary aim of this study was to determine the feasibility of trialling this new approach as an asthma self-management intervention. The secondary aim was to report the effect of the intervention and comparator websites on various self-reported outcomes, including measures of self-efficacy, selfmanagement and health status. Ethical approval for this study was provided by the NHS Health Research Authority Research Ethics Committee, reference 13/NW/0162. 


\section{METHODS}

The trial protocol is provided as online supplementary file 1 .

\section{Settings and participants}

People with chronic asthma were recruited from nine primary care practices in two regions of England between June 2013 and November 2013, facilitated by the local primary care research networks. Individuals were eligible if they had been clinically diagnosed with asthma as coded in their primary care electronic record and prescribed inhaled corticosteroids for at least 3 months in the previous year, were aged 18 years or over, lived in England and had internet access. The local primary care research network identified primary care practices on our behalf and practices were sent the inclusion and exclusion criteria and asked to identify patients who met the criteria. Individuals were then sent an information pack. GPs excluded people who were unable to read English, who were terminally ill or had another significant disease or disorder likely to affect their ability to participate in the study. For full inclusion criteria, see box 1 .

\section{Study design and procedure}

The study formed part of a larger programme of work investigating the value of online patient experiences. ${ }^{33}$ We conducted a phase II pilot randomised single-blind trial with the aim of assessing the feasibility and impact of patient-experience (PEx)-based websites compared with matched health information websites that did not contain experiential information. We did this for three conditions: smoking cessation; asthma; and caring for someone with multiple sclerosis. Target recruitment was 300 participants, 100 participants per condition. The

\section{Box 1 Inclusion and exclusion criteria}

Inclusion criteria
Male or female aged 18 or over
People who have been clinically diagnosed asthma as coded in
their primary care electronic record, and who have been pre-
scribed inhaled corticosteroids for at least 3 months in the previ-
ous year
Willing and able to give informed consent for participation in the
study
Resident in England
Have access to the internet and are able to use websites
Exclusion criteria
People who are terminally ill
People who cannot understand English
People who have previously entered the study under the same/
another condition
People who have another significant disease or disorder which, in
the opinion of the GP, may either put that person at risk because
of participation in the study, or may influence the result of the
study, or affect that person's ability to participate in the study
Another person in the household is already enrolled in the study

smoking cessation and carers case studies will be reported separately. To minimise the risk of contamination across the three studies, each recruited in different settings and only one person per household was eligible to take part in any of the three studies.

Participants who indicated interest and met the inclusion criteria were sent a patient information sheet and consent form by post to be signed and returned to the research office in a reply-paid envelope. Once consent had been received, participants' details were entered into a secure Trial Management Portal and they were emailed a unique 'Welcome Code' with a link to the trial registration web page (see online supplementary file 2). An automatic email was generated if the participant had not used their code within a week, inviting the participant to visit the trial registration page. Participants who no longer wished to take part could simply ignore this reminder. The email contained a link to access the trial registration page where the participant was invited to complete online baseline questionnaires. Completion of baseline measures generated an invitation to create a unique user ID and password and randomisation to access either the intervention or comparator website, for a period of 2 weeks. Randomisation used a computer-generated random number sequence in a 1:1 ratio and was carried out by stratified (on the three conditions) block randomisation with varying block sizes. A randomisation list was generated and uploaded to the online trial portal to ensure treatment concealment. The investigators were not aware of the randomisation result on the system. The randomisation list, which was password-protected, was kept in confidence.

Participants were able to logon and access the website interventions as much or as little as they wanted. At the end of the 2-week period, participants were invited (by email) to complete final follow-up measures, online. Up to two emails and one telephone call were used to remind those who did not initially respond. Participants' usage of their allocated website was also tracked. In addition to the statistical analysis, we also conducted interviews with participants in this trial and with participants in the two other trials exploring the value of online personal experiences and a joint analysis of these will be reported separately. Participants could not be blind to the nature of the website to which they were allocated, but they did not know whether they were receiving the comparator or the intervention website, only that we were evaluating two approaches to giving health information. The analysis was blind to allocation.

\section{Intervention design}

The intervention was a multimedia website developed by the University of Oxford Health Experiences Research Group and the Healthtalk.org charity. An advisory panel of lay representatives, leading researchers and clinicians also provided extensive input. The website included thematic analyses of key topics from interviews with a purposive sample of 40 people with asthma about their 
experiences of their condition. ${ }^{34}$ Topics are illustrated with interview extracts in short video, audio and written formats. Video and audio extract varied in length but were typically $2 \mathrm{~min}$ long. Examples of the 25 topics published on the website include 'early signs and symptoms', 'what asthma feels like', 'dealing with health professionals', 'emotions and coping' and 'advice to others'. The content was presented on the website in such a way that users were able to browse topics according to relevance and interest. The content was not personalised to individual users and information flow was not guided or 'tunnelled' in any way: all intervention users experienced the same website and could navigate content in any chosen order. To maintain a stable intervention, we did not include user interactivity that could change the content of the website, other than the option to provide feedback to the research team. Users were able to comment on and rate each page if desired.

To compare this intervention site with a 'gold standard' matched alternative, we provided a control website based on 'facts and figures' about asthma self-management. We constructed a new site which closely resembled the design and features of the intervention yet was populated with the asthma self-management information taken from NHS Choices (http://www.nhs.uk), as the authoritative provider of online health information in the UK. Screenshots of both sites are provided as online supplementary file 3 .

\section{Outcome measures}

As a feasibility study, our primary measures concerned the number of participants consented and recruited, the usage of the websites (in terms of numbers of logins, page views and time on site) and the numbers with completed outcome measures or lost to follow-up. Secondary outcomes used the following self-report questionnaires. The Partners in Health (PIH) measure is a 12-item questionnaire which asks participants to rate how well they look after themselves and manage their health condition, on an 8-point scale. The Chronic Disease Self-Efficacy Scale (CDSES) is a 6-item questionnaire which asks respondents to rate their confidence in being able to undertake certain activities, on a 10-point scale. A single-item asthma control question was included, which asked how participants rated their asthma control over the past 2 weeks. The SF36 (including physical and mental dimensions and all subscales) measures health status. Finally, we used the E-Health Impact Questionnaire (eHIQ), a validated measure which captures the attitudes of respondents towards the website they have recently viewed, giving scores on three subscales: confidence and identification, information and presentation, and understanding and motivation. ${ }^{35}$

\section{Sample size and statistical analyses}

The target sample size for this asthma study was 100 participants. The primary determinant of this sample size was to demonstrate feasibility. In terms of effect sizes, based on a balanced randomisation of the intervention: comparator groups in a ratio of 1:1 (ie, 50 intervention, 50 comparator), the study would detect potential large effects of the intervention: for dichotomous outcomes, these were equivalent to relative risks of 2.1 or above for a baseline rate of $30 \%$ or less, given an $\alpha$ of 0.05 and $90 \%$ power; for continuous outcomes, these detectable differences would be of the order of 0.4 SDs based on the same power and significance. Feasibility outcome measures were summarised using descriptive statistics such as rates reported as percentages. Formal hypothesis testing was not performed since this was a feasibility study and was not intended to power for assessing evidence of significant treatment effect, but estimated difference in outcome measures of efficacy and corresponding 95\% CIs were calculated using analysis of covariance (ANCOVA) adjusting for baseline values.

\section{RESULTS}

A total of 200 invitations were sent in response to expressions of interest in the study, and 150 individuals $(75 \%)$ completed registration (ie, consented and completed baseline questionnaires). Two participants withdrew before randomisation, leaving 148 randomised participants (recruitment rate of 148/150=99\%). Seventy-three of these (49\%) were allocated to the patient experience website. Of the randomised participants, 25 of 148 (17\%) were lost to follow-up. See CONSORT flow diagram (figure 1).

The baseline demographics and asthma status of randomised participants are presented in tables 1 and 2 . Participants' baseline asthma status was measured using the Asthma Control Test (ACT), which measures control using five items with a five-point scale. Over $90 \%$ of the cohort was white, and the majority reported good to excellent internet abilities. Eighty-seven of the 148 participants $(59 \%)$ were women. Most participants did not have major problems with their asthma. The majority reported that their asthma had not prevented them from getting things performed at home or at work over the past 4 weeks, with $80.4 \%$ stating that they had experienced very little or no shortness of breath. The use of reliever inhalers was spread among the sample, with $25.7 \%$ using a reliever inhaler at least once daily and $14.2 \%$ using one 2-3 times/week. About $31.8 \%$ of the sample had not used an inhaler at all in the previous 4 weeks. About $82.4 \%$ of the sample reported that their asthma was 'well' or 'completely' controlled.

The usage of the websites is shown in table 3 and online supplementary figures S1 and S2. Usage data refer to the number of logins, total number of pages visited and time spent on the participant's allocated site. It does not include time spent completing baseline or follow-up measures. The median number of logins in the 2-week period for both sites was 2, and the median number of page views was 14 for the intervention site and 15 for the comparator site. The median duration of the use of the intervention site was $15 \mathrm{~min}$, and for the 
Invites sent to eligible participants $(\mathrm{N}=200)$

Excluded $(\mathrm{N}=50)$

Did not complete registration $(\mathrm{n}=50)$

Registration completed $(\mathrm{N}=150)$

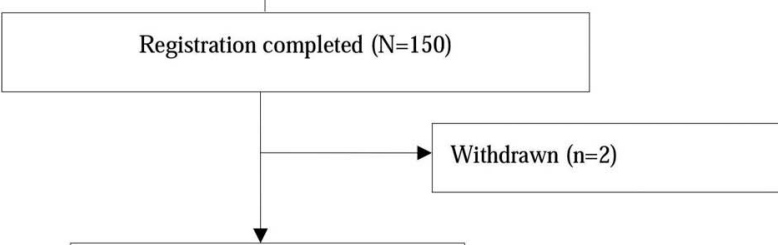

Randomised ( $\mathrm{N}=148)$

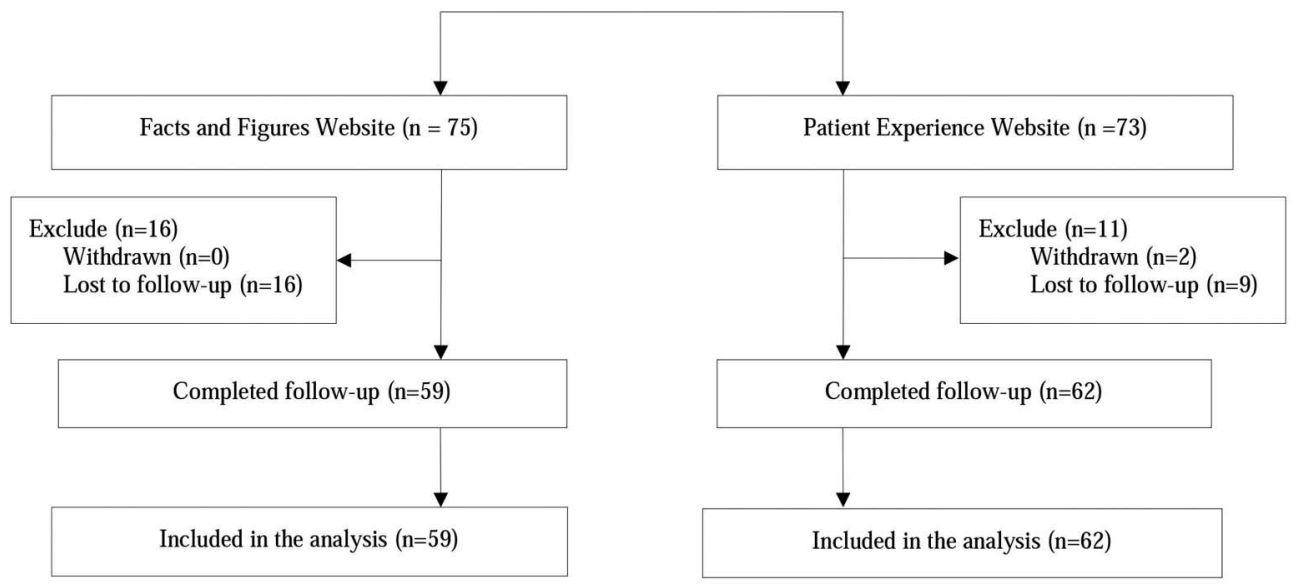

Figure 1 CONSORT flow diagram.

comparator site was $19 \mathrm{~min}$. Three users never logged in to their allocated site, all in the intervention group.

The PIH baseline mean score (SD) for the intervention group was $6.69(0.888)$ and for the comparator group 6.81 (0.864); at 2-week follow-up, these scores were $6.84(0.863)$ and 6.97 (0.996), respectively. Both groups had high mean PIH scores, indicating good management of their condition. The mean (SD) change from baseline was an increase of $0.06(0.61)$ in the intervention group and an increase of 0.03 (0.64) in the comparator group. Treatment effect (mean differences with CI) estimated using ANCOVA adjusting for baseline mean PIH scores showed that there was very little difference between the intervention and comparator group (the former on average scored lower compared with their baseline by -0.02 points, $95 \%$ CI -0.25 to 0.21 ), although CIs are wide and incorporate values representing an increase in the intervention group.

The findings from the other exploratory comparisons of asthma-specific outcome measures are shown in tables 4 and 5 . Table 4 shows the baseline and follow-up scores and change scores for the CDSES. The ANCOVA analysis estimated the mean difference between groups. Since the model was adjusted for baseline score, the estimated adjusted treatment effects should be identical on change scores or follow-up scores. Table 5 shows the answers provided for the single-item control question. For these measures, there were very minor differences between groups with no clear indication of a differential effect between groups.

Table 6 shows that the e-HIQ part B scores were also very similar between groups.

All participants showed an improvement in overall health state from baseline in the Physical and Mental component of the SF36, with a greater improvement in overall health state seen in the intervention group. The mean differences between the groups were compared adjusting for baseline scores (ANCOVA analysis, $n=119$ participants with full data), showing that the intervention group on average saw an increase in PCS of 0.20 points (95\% CI -1.45 to 1.85 ) compared with the comparator group. Similarly for the MCS, the intervention group on average saw an increase of 0.85 points $(95 \%$ CI -1.07 to 2.75 ) compared with the comparator group.

\section{DISCUSSION}

The primary objective of this study was to determine the feasibility of using the RCT paradigm to measure the impact of a novel intervention using patient experiences 
Table 1 Baseline demographic of the study population

\begin{tabular}{|c|c|c|c|c|}
\hline & \multicolumn{2}{|c|}{ Comparator $(n=75)$} & \multicolumn{2}{|c|}{ Intervention $(\mathrm{n}=73)$} \\
\hline & $\mathbf{N}$ & $(\%)$ & $\mathbf{N}$ & $(\%)$ \\
\hline \multicolumn{5}{|l|}{ Age } \\
\hline Mean (SD) $\{\min -\max \}$ & \multicolumn{2}{|c|}{$55.7(13.9)\{19-84\}$} & \multicolumn{2}{|c|}{$58.2(11.7)\{27-77\}$} \\
\hline \multicolumn{5}{|l|}{ Gender } \\
\hline Female & 41 & $(54.7)$ & 46 & $(63.0)$ \\
\hline Male & 34 & (45.3) & 27 & $(37.0)$ \\
\hline \multicolumn{5}{|l|}{ Self-rated ability to use the internet } \\
\hline Excellent & 26 & (34.7) & 18 & $(24.7)$ \\
\hline Good & 35 & (46.7) & 34 & (46.6) \\
\hline Fair & 12 & (16.0) & 17 & (23.3) \\
\hline Poor & 2 & $(2.7)$ & 3 & $(4.1)$ \\
\hline Bad & 0 & 0 & 1 & $(1.4)$ \\
\hline \multicolumn{5}{|l|}{ Internet use } \\
\hline At least once a day & 49 & (65.3) & 37 & $(50.7)$ \\
\hline Several times a week & 19 & (25.3) & 21 & (28.8) \\
\hline Once a week & 6 & $(8.0)$ & 6 & $(8.2)$ \\
\hline Less than once a week & 1 & (1.3) & 9 & (12.3) \\
\hline \multicolumn{5}{|l|}{ Ethnicity } \\
\hline Not reported & 3 & $(4.0)$ & 2 & $(2.7)$ \\
\hline White-English/Welsh/Scottish/Northern Irish/British & 66 & (88.0) & 66 & $(90.4)$ \\
\hline White-any other White background & 4 & $(5.3)$ & 1 & $(1.4)$ \\
\hline Mixed-White and Black African & 0 & 0 & 1 & $(1.4)$ \\
\hline Asian-Indian & 1 & $(1.3)$ & 2 & $(2.7)$ \\
\hline Black-African & 1 & (1.3) & 0 & 0 \\
\hline Black-Caribbean & 0 & 0 & 1 & $(1.4)$ \\
\hline
\end{tabular}

for self-management of chronic asthma. Recruitment and consent rates were high in this study, demonstrating trial feasibility. It is possible to speculate that strong response rates were achieved thanks to the combined actions of a proactive primary care research network and engaged general practitioners who were able to identify a condition which is readily coded in the primary care system. The intervention was delivered successfully, and there were no adverse events or protocol deviations. As is frequently seen in trials of fully automated online interventions, actual use of the intervention was relatively low: the median number of logins was 2 and the median amount of time spent on the site was $17 \mathrm{~min}$, although there was wide variation, with usage data skewed by some participants spending a long time on the website. Collection of the usage data was valuable in exploring whether or not simple exposure to the website was sufficient to have an effect on the outcome measures and given the low level of usage observed, future work needs to maximise user engagement with the intervention. We were not able to record which specific pages of the intervention were most used, and again it would be valuable in future work to understand more about this when interpreting the effect of using the website. Retention rates at 2 weeks were moderately high (82\%). Future work could include additional forms of automated contact such as text message prompts and reminders to reduce attrition further, without compromising the cost advantage of having no face-to-face contact.

This study was not designed to assess efficacy, and comparisons between randomised groups showed no significant differences on any of the measures. This is not surprising as the comparator group received access to what is considered to be excellent factual information about management of chronic asthma. Importantly, there were no adverse events from the novel intervention. Future work should take an explicitly pragmatic approach: one way of doing this would be to explore whether the experiential element could be incorporated as an adjunct rather than as an alternative, investigating whether experiential information has added value alongside 'facts and figures'.

Future work should consider the nature of how the sites are used. Allocating participants to a 2-week 'dose' of a website and then measuring its impact does not reflect real-world information behaviour or everyday internet use. Future work needs to reflect 'real-life' engagement with digital resources. This is challenging within an RCT design which generally packages websites as a static experience, so that everyone in the group receives the same intervention. In practice, people search, reflect on, personally curate and 'consume' multiple information sources within an off-line and online landscape in multiple ways at different stages of an illness. Further theoretical and methodological work may be needed to consider the issues of 'dosage' and 'exposure' in the context of online health information. For example, future work could explore the potential value to users of being able to contribute to an experience-based intervention: the current study used a set of personal accounts which had been solicited and 
Table 2 Baseline characteristics from the Asthma Control Test (ACT) questionnaire

\begin{tabular}{|c|c|c|}
\hline $\begin{array}{l}\text { All participants } \\
(\mathrm{N}=148)\end{array}$ & $\begin{array}{l}\text { Facts and figures } \\
(n=75)\end{array}$ & $\begin{array}{l}\text { Patient experience } \\
(n=73)\end{array}$ \\
\hline $\begin{array}{ll}\mathbf{N} & (\%)\end{array}$ & $\begin{array}{ll}\mathbf{N} & (\%)\end{array}$ & $\begin{array}{ll}\mathbf{N} & (\%)\end{array}$ \\
\hline
\end{tabular}

How often did your asthma keep you from getting as much performed at work, school or home?

$\begin{array}{lllllll}\text { All of the time } & 1 & (0.7) & 1 & (1.3) & 0 & 0 \\ \text { Most of the time } & 5 & (3.4) & 3 & (4.0) & 2 & (2.7) \\ \text { Some of the time } & 11 & (7.4) & 3 & (4.0) & 8 & (11.0) \\ \text { A little of the time } & 33 & (22.3) & 16 & (21.3) & 17 & (23.3) \\ \text { None of the time } & 98 & (66.2) & 52 & (69.3) & 46 & (63.0) \\ \text { How often have you had shortness of breath? } & 11 & (7.4) & & & & \\ \text { More than once a day } & 6 & (4.1) & 1 & (1.0) & 5 & (6.8) \\ \text { Once a day } & 12 & (8.1) & 7 & (9.3) & 5 & (6.8) \\ \text { Three to six times a week } & 63 & (42.6) & 36 & (48.0) & 27 & (6.8) \\ \text { Once or twice a week } & 56 & (37.8) & 25 & (33.3) & 31 & (42.0) \\ \text { Not at all } & \end{array}$

How often did your asthma symptoms (wheezing, coughing, chest tightness, shortness of breath) wake you up at night or earlier than usual in the morning?

\begin{tabular}{lllllll} 
Four or more times per day & 9 & $(6.1)$ & 4 & $(5.3)$ & 5 & $(6.8)$ \\
Two to three nights a week & 8 & $(5.4)$ & 5 & $(6.7)$ & 3 & $(4.1)$ \\
Once a week & 4 & $(2.7)$ & 2 & $(2.7)$ & 2 & $(2.7)$ \\
Once or twice a week & 37 & $(25.0)$ & 17 & $(22.7)$ & 20 & $(27.4)$ \\
Not at all & 90 & $(60.8)$ & 47 & $(62.7)$ & 43 & $(58.9)$ \\
How often have you used your reliever inhaler & $\left(\begin{array}{l}\text { (usually } \\
\text { blue)? }\end{array}\right.$ & & & & & \\
Three or more times per day & 12 & $(8.1)$ & 5 & $(6.7)$ & 7 & $(9.6)$ \\
One or two times per day & 26 & $(17.6)$ & 13 & $(17.3)$ & 13 & $(17.8)$ \\
Two or three times per week & 21 & $(14.2)$ & 11 & $(14.7)$ & 10 & $(13.7)$ \\
Once a week or less & 42 & $(28.4)$ & 27 & $(36.0)$ & 15 & $(20.5)$ \\
Not at all & 47 & $(31.8)$ & 19 & $(25.3)$ & 28 & $(38.4)$ \\
How would you rate your asthma control? & & & & & & \\
Not controlled & 2 & $(1.4)$ & 1 & $(1.3)$ & 1 & $(1.4)$ \\
Poorly controlled & 2 & $(1.4)$ & 1 & $(1.3)$ & 1 & $(1.4)$ \\
Somewhat controlled & 22 & $(14.9)$ & 9 & $(12.0)$ & 13 & $(17.8)$ \\
Well controlled & 72 & $(48.6)$ & 41 & $(54.7)$ & 31 & $(42.5)$ \\
Completely controlled & 50 & $(33.8)$ & 23 & $(30.7)$ & 27 & $(37.0)$ \\
\hline
\end{tabular}

Table 3 Usage data for comparator and intervention websites

\begin{tabular}{|c|c|c|c|}
\hline & All participants* $(\mathrm{N}=145)$ & Facts and figures $(n=75)$ & Patient experience* $(n=70)$ \\
\hline \multicolumn{4}{|c|}{ Total number of logins to website } \\
\hline $\begin{array}{l}\text { Median (min-max) } \\
\{I Q R\}\end{array}$ & $\begin{array}{l}2(1-48) \\
\{2-3\}\end{array}$ & $\begin{array}{l}2(1-32) \\
\{2-3\}\end{array}$ & $\begin{array}{l}2(1-48) \\
\{2-4\}\end{array}$ \\
\hline \multicolumn{4}{|c|}{ Total number of pages visited } \\
\hline $\begin{array}{l}\text { Median (min-max) } \\
\{I Q R\}\end{array}$ & $\begin{array}{l}15(1-65) \\
\{5-27\}\end{array}$ & $\begin{array}{l}15(1-65) \\
\{5-27\}\end{array}$ & $\begin{array}{l}14(1-62) \\
\{5-27\}\end{array}$ \\
\hline \multicolumn{4}{|c|}{ Total duration on site $(\min ) \dagger$} \\
\hline $\begin{array}{l}\text { Median (min-max) } \\
\{\mathrm{IQR}\}\end{array}$ & $\begin{array}{l}17(0.5-471) \\
\{5-42\}\end{array}$ & $\begin{array}{l}19(0.5-471) \\
\{5-41)\end{array}$ & $\begin{array}{l}15(0.5-119) \\
\{4-43\}\end{array}$ \\
\hline
\end{tabular}

curated so as to comply with the RCT paradigm. In reality, people who are managing chronic asthma may wish to contribute and comment as well as look at those from others; this may offer more realistic interaction and reflects the real-life evolution of such websites.

It is important to note characteristics of the cohort which would likely influence outcomes. Although participants were eligible if they had been clinically diagnosed with asthma and prescribed inhaled corticosteroids for at least 3 months in the previous year, the vast majority of participants had lived with asthma for much longer. No recently diagnosed patients were randomised. Most of the people who volunteered to take part were experienced in managing their condition and had their 
Table 4 Summary statistics for the Chronic Disease Self-Efficacy Scale (CDSES) summary scores by randomised group and analysis of covariance for the asthma cohort

\begin{tabular}{|c|c|c|c|c|c|c|}
\hline & \multicolumn{3}{|c|}{ Facts and figures $(n=75)$} & \multicolumn{3}{|c|}{ Patient experience $(n=73)$} \\
\hline & $\overline{\mathbf{n}}$ & Mean (SD) & $\{$ Min-max $\}$ & $\bar{n}$ & Mean (SD) & $\{$ Min-max $\}$ \\
\hline \multicolumn{7}{|l|}{ Chronic Disease Self-Efficacy Scale } \\
\hline Baseline CDSES scores* & 74 & $8.207(1.530)$ & $\{2.33-10.0\}$ & 73 & $8.231(1.611)$ & $\{1.83-10.0\}$ \\
\hline 2-week CDSES scorest & 59 & $8.401(1.501)$ & $\{4.00-10.0\}$ & 62 & $8.238(1.389)$ & $\{4.40-10.0\}$ \\
\hline Change in mean CDSES scores & 58 & $0.093(0.951)$ & $\{-3.00-2.33\}$ & 62 & $-0.068(0.910)$ & $\{-1.33-3.67\}$ \\
\hline ANCOVA & & & $\begin{array}{l}\text { Adjusted mean } \\
\text { diff }\end{array}$ & & & \\
\hline $95 \% \mathrm{Cl}$ & & $\begin{array}{l}\text { Patient } \\
\text { experience }\end{array}$ & 120 & \multicolumn{3}{|c|}{-0.1574} \\
\hline-0.4661 to 0.1512 & & & & & & \\
\hline
\end{tabular}

${ }^{*}$ One participant only completed two items, not included.

†ncludes ( $\mathrm{n}=117$ participants who completed all 6 items and $n=4$ participants who completed 5 items).

$\ddagger$ Adjusted for mean baseline CDSES scores.

Table 5 Counts and percentages of responses for self-rated asthma control by randomised group at follow-up

\begin{tabular}{|c|c|c|c|c|c|c|}
\hline & \multicolumn{2}{|c|}{$\begin{array}{l}\text { All participants } \\
(\mathrm{N}=148)\end{array}$} & \multicolumn{2}{|c|}{$\begin{array}{l}\text { Facts and figures } \\
(n=75)\end{array}$} & \multicolumn{2}{|c|}{$\begin{array}{l}\text { Patient experience } \\
(n=73)\end{array}$} \\
\hline & $\mathbf{N}$ & (\%) & $\overline{\mathbf{N}}$ & (\%) & $\overline{\mathbf{N}}$ & (\%) \\
\hline \multicolumn{7}{|c|}{ Self-rated asthma control during the past 2 weeks } \\
\hline Not reported ${ }^{*}$ & 27 & (18.2) & 16 & (21.3) & 11 & (15.1) \\
\hline Poorly controlled & 2 & (1.4) & 1 & (1.3) & 1 & (4.1) \\
\hline Somewhat controlled & 11 & (7.4) & 8 & (10.7) & 3 & (4.1) \\
\hline Well controlled & 61 & (41.2) & 26 & (34.7) & 35 & (47.9) \\
\hline Completely controlled & 47 & (31.8) & 24 & (32.0) & 23 & (31.5) \\
\hline
\end{tabular}

Table 6 Mean (SD) of E-Health Impact Questionnaire (eHIQ) part 2 scores for the intervention and comparator group at 2-week follow-up

\begin{tabular}{|c|c|c|c|c|}
\hline & $\begin{array}{l}\text { Comparator } \\
(n=57 / 75)\end{array}$ & $\begin{array}{l}\text { Intervention } \\
(n=61 / 73)\end{array}$ & $\begin{array}{l}\text { Unadjusted mean } \\
\text { difference }\end{array}$ & $95 \% \mathrm{Cl}$ \\
\hline $\begin{array}{l}\text { eHIQ part } 2 \text { overall scores } \\
\text { Subscales }\end{array}$ & $67.3(12.46)$ & $65.8(11.29)$ & -1.473 & -5.802 to 2.855 \\
\hline $\begin{array}{l}\text { Confidence and } \\
\text { identification }\end{array}$ & $59.7(17.03)$ & 58.7 (14.67) & -1.052 & -6.836 to 4.732 \\
\hline $\begin{array}{l}\text { Information and } \\
\text { presentation }\end{array}$ & $76.1(11.38)$ & 74.5 (10.56) & -1.462 & -5.412 to 2.487 \\
\hline $\begin{array}{l}\text { Understanding and } \\
\text { motivation }\end{array}$ & 64.3 (15.22) & $63.9(13.66)$ & -0.334 & -5.535 to 4.868 \\
\hline
\end{tabular}

asthma well controlled. They were also, not surprisingly, people who were comfortable and confident about using the internet. Thus, while they were willing and able to take part in a study of online health information, they were not a group who were likely 'in the real world' to be searching online for health information or connection with other people living with asthma, in order to support their own asthma management. This has clear implications for further research: how do you recruit those people who perhaps are less likely to be motivated to take part in the research but are more likely to need help with self- management? Further work is required to identify which people with asthma are most likely to benefit from such an intervention: for example, experiential information of this type and for this condition may be best suited to those who are newly diagnosed or experiencing a change in symptoms.

\section{CONCLUSION}

Asthma remains a major public health problem internationally and can profoundly impact on physical and 
psychological well-being. Effective self-management of chronic asthma is associated with improved outcomes. The sharing of personal experiences online is a relatively new phenomenon and we have attempted to examine the value of this in a novel intervention to support self-management as part of an RCT. We have demonstrated that this is feasible and not shown any harm from the intervention, compared with a gold standard 'facts and figures' website. However, future work needs to consider how to deliver such an intervention in a more pragmatic fashion reflecting 'real world' internet use, and assessing the value of such an intervention as an adjunct rather than an alternative to other sources of information. Future work, as with all new selfdirected internet interventions, is also needed to determine the best methods to maximise engagement and adherence.

\section{Twitter Follow Nikki Newhouse @nikkinewhouse}

Acknowledgements The authors are very grateful for the guidance provided by our Trial Steering Committee (TSC) chaired by Professor Elizabeth Murray. The authors thank all the participants who took part in the study. The authors thank the University of Oxford Health Experiences Research Group and the Healthtalk.org charity, particularly those who carried out the narrative interviews and contributed to the intervention and comparator sites. Many thanks also to Professor Sally Wyke for her help with the coding frame for the interviews. The iPEx study group is composed of: University of Oxford (SZ, JP, LL, Andrew Farmer, Crispin Jenkinson, Rafael Perera, NN, Ruth Sanders, AM, Laura Griffith, Susan Kirkpatrick, Nicolas Hughes, Laura Kelly, Braden O'Neill, Ally Bradley, MD, L-MY), University of Edinburgh (Fadhila Mazanderani), University of Northumbria (Pamela Briggs, Elizabeth Sillence, Claire Hardy), University of Sussex (Peter Harris), University of Glasgow (Sally Wyke), Department of Health (Robert Gann), Oxfordshire Primary Care Trust (Sula Wiltshire) and User advisor (Margaret Booth). In addition to those named above, the authors thank Peter Davidson of the National Evaluation and Trials Coordinating Centre, and Maria Breen formerly of the Oxford University Primary Care Clinical Trials Unit, for their advice. LL is supported by NIHR Oxford Biomedical Research Centre.

Contributors JP and SZ led planning and development of the full programme of work with support from AM, NN and LL. NN, AM and MD were responsible for recruitment, MD was responsible for management of the online trial portal. L-MY led data analysis and interpretation with support from SJ. The wider iPEx study group provided extensive input and support at all stages of intervention development, delivery and evaluation. NN drafted the manuscript with additional input from JP and SZ. All authors critically reviewed the manuscript, contributing important intellectual content and approved the final manuscript.

Funding The iPEx programme presents independent research funded by the UK National Institute for Health Research (NIHR) under its Programme Grants for Applied Research funding scheme (RP-PG-0608-10147).

Disclaimer The views expressed in this paper are those of the authors, representing iPEx, and not necessarily those of the NHS, the NIHR or the Department of Health.

\section{Competing interests None declared.}

Ethics approval NHS Health Research Authority Research Ethics Committee.

Provenance and peer review Not commissioned; externally peer reviewed.

Data sharing statement The data sets analysed during the current study are available from the principal investigator (JP) on reasonable request. All trial data have been described in this paper.

Open Access This is an Open Access article distributed in accordance with the Creative Commons Attribution Non Commercial (CC BY-NC 4.0) license, which permits others to distribute, remix, adapt, build upon this work noncommercially, and license their derivative works on different terms, provided the original work is properly cited and the use is non-commercial. See: http:// creativecommons.org/licenses/by-nc/4.0/

\section{REFERENCES}

1. Ampon RD, Williamson M, Correll PK, et al. Impact of asthma on self-reported health status and quality of life: a population based study of Australians aged 18-64. Thorax 2005;60:735-9.

2. Gallefoss F, Bakke PS, Rsgaard PK. Quality of life assessment after patient education in a randomised controlled study on asthma and chronic obstructive pulmonary disease. Am J Respir Crit Care Med 1999;159:812-17.

3. Ring N, Jepson R, Hoskins G, et al. Understanding what helps or hinders asthma action plan use: a systematic review and synthesis of the qualitative literature. Patient Educ Couns 2011:85:e131-43.

4. van der Palen J, Klein JJ, Rovers MM. Compliance with inhaled medication and self-treatment guidelines following a self-management programme in adult asthmatics. Eur Respir $J$ 1997;10:652-7.

5. Thoonen BP, Schermer TR, Jansen M, et al. Asthma education tailored to individual patient needs can optimise partnerships in asthma self-management. Patient Educ Couns 2002;47:355-60.

6. Koning CJ, Maillé AR, Stevens I, et al. Patients' opinions on respiratory care: do doctors fulfill their needs? J Asthma 1995;32:355-63.

7. Heiner MM. Key barriers to optimal management of adult asthma in Australia: physician and patient perspectives. Curr Med Res Opin 2007;23:1799-807.

8. Bowles L. How much should patients be told about their medication? Br J Nurs 1996;5:157-61.

9. Raynor DK, Savage I, Knapp P, et al. We are the experts: people with asthma talk about their medicine information needs. Patient Educ Couns 2004;53:167-74.

10. Andreassen HK, Bujnowska-Fedak MM, Chronaki CE, et al. European citizens' use of E-health services: a study of seven countries. BMC Public Health 2007;7:53.

11. Newhouse N, Lupiáñez-Villanueva F, Codagnone C, et al. Patient use of email for health care communication purposes across 14 European countries: an analysis of users according to demographic and health-related factors. J Med Internet Res 2015;17:e58.

12. Fox S, Duggan M. The Diagnosis Difference. Pew Research Centre. November 2013. http://www.pewinternet.org/2013/11/26/ the-diagnosis-difference/ (accessed 29 Jul 2015).

13. Croft DR, Peterson MW. An evaluation of the quality and contents of asthma education on the World Wide Web. Chest 2002;121:1301-7.

14. McLean S, Chandler D, Nurmatov U, et al. Telehealthcare for asthma: a Cochrane review. CMAJ 2011;183:E733-42.

15. Marcano Belisario JS, Huckvale K, Greenfield G, et al. Smartphone and tablet self-management apps for asthma. Cochrane Database Syst Rev 2013;(11):CD010013

16. Morrison D, Wyke S, Agur K, et al. Digital asthma self-management interventions: a systematic review. J Med Internet Res 2014;16:e51.

17. Morrison D, Wyke S, Saunderson K, et al. Findings from a pilot Randomised trial of an Asthma Internet Self-management Intervention (RAISIN). BMJ Open 2016;6:e009254.

18. Ziebland S, Wyke S. Health and illness in a connected world: how might sharing experiences on the internet affect people's health? Milbank Q 2012;90:219-49.

19. Sillence $E$, Hardy C, Briggs $P$, et al. How do people with asthma use Internet sites containing patient experiences? Patient Educ Couns 2013;93:439-43.

20. Entwistle VA, France EF, Wyke S, et al. How information about other people's personal experiences can help with healthcare decision-making: a qualitative study. Patient Educ Couns 2011;85: e291-8.

21. Pérez M, Sefko JA, Ksiazek D, et al. A novel intervention using interactive technology and personal narratives to reduce cance disparities: African American breast cancer survivor stories. J Cancer Surviv 2014;8:21-30.

22. Kreuter MW, Holmes K, Alcaraz K, et al. Comparing narrative and informational videos to increase mammography in low-income African American women. Patient Educ Couns 2010;81(Suppl): S6-14.

23. Ashton $\mathrm{CM}$, Houston TK, Williams $\mathrm{JH}$, et al. A stories-based interactive DVD intended to help people with hypertension achieve blood pressure control through improved communication with their doctors. Patient Educ Couns 2010;79:245-50. 
24. Gibson PG, Powell H, Coughlan J, et al. Self-management education and regular practitioner review for adults with asthma. Cochrane Database Syst Rev 2003;(1):CD001117.

25. British Thoracic Society; Scottish Intercollegiate Guidelines Network British guideline on the management of asthma. Thorax 2014;69 (Suppl 1):1-192.

26. Bateman ED, Boulet L-P, Cru AA, et al. Global strategy for asthma management and prevention. Updated 2010. Global Initiative for Asthma.

27. Kirby SE, Miles C, Arden-Close E, et al. Barriers and facilitators to effective self-management of asthma-a systematic review. Thorax 2014;69:A96.

28. Eakin MN, Rand CS. Improving patient adherence with asthma self-management practices: what works? Ann Allergy Asthma Immunol 2012;109:90-2.

29. Huckvale K, Car M, Morrison C, et al. Apps for asthma selfmanagement: a systematic assessment of content and tools. BMC Med 2012;10:144

30. Mo PK, Coulson NS. Exploring the communication of social support within virtual communities: a content analysis of messages posted to an online HIV/AIDS support group. Cyberpsychol Behav 2008:11:371-4.

31. Rozmovits L, Ziebland S. What do patients with prostate or breast cancer want from an Internet site? A

qualitative study of information needs. Patient Educ Couns 2004;53:57-64.

32. van Uden-Kraan CF, Drossaert CH, Taal E, et al. Self-reported differences in empowerment between lurkers and posters in online patient support groups. J Med Internet Res 2008;10:e18.

33. Ziebland S, Powell J, Briggs $P$, et al. Examining the role of patients' experiences as a resource for choice and decision-making in healthcare: a creative, inter-disciplinary mixed method study in digital health. Programme Grants Appl Res 2016 (in press).

34. Ziebland S, McPherson A. Making sense of qualitative data analysis: an introduction with illustrations from DIPEx (personal experiences of health and illness). Med Educ 2006;40:405-14.

35. Kelly L, Jenkinson C, Ziebland S. Measuring the effects of online health information for patients: item generation for an e-health impact questionnaire. Patient Educ Couns 2013;93:433-8. 